\title{
Exploring Company's Activities in the Field of CSR: The Case of Starbucks
}

DOI: http://dx.doi.org/10.12775/JCRL.2019.006

\author{
EDYTA GOZDAN \\ Faculty of Economic Sciences and Management, Nicolaus Copernicus \\ University, Toruń, Poland \\ e-mail: gozdanedyta@gmail.com
}

\begin{abstract}
Agata Sudolska
Faculty of Economic Sciences and Management, Nicolaus Copernicus

University, Toruń, Poland

e-mail: aga@econ.umk.pl
\end{abstract}

\begin{abstract}
Recently CSR has gained companies' attention due to its strategic importance. In the contemporary economy, the enterprises, especially those that are global corporations, are highly involved in several activities focused on meeting both societal and environmental needs. As caring about the better future for next generations, the companies implementing CSR aim at compensating the side effects related their operations. On the other hand, they aim at building their brands perceived as supporting local communities and engaging in particular environmental projects. One of such global corporations highly involved in CSR field is Starbucks. The aim of the study is to is to explore Starbucks' activities in the field of CSR. The research process is driven by the three following research questions: (1) What are the main areas of Starbucks' involvement in CSR activities? (2) What are the main Starbucks' company objectives in the field of CSR? (3) How does Starbucks implement CSR activities following TBL concept? The exploratory single case study analysis of Starbucks company is applied to answer research questions and achieve the aim of the study. The research results presented in the paper indicate that Starbucks carries out several activities focused on supporting different communities as well
\end{abstract}


as prove that the company is engaged in various projects dedicated to environment protection and climate change resistance.

Keywords: corporate social responsibility, CSR, case study, Starbucks.

\section{Introduction}

The business world is facing the challenge of corporate social responsibility (CSR) wherever it turns nowadays. Based both on literature studies and practice observation one can easily note that CSR, understood as the voluntary inclusion of stakeholder needs in the company's strategy, is becoming an increasingly recognizable phenomenon. Economic growth and profit maximization have been shaped over the years as the main goals of business and the basis for the development of economic progress but also the origin for generating greater social prosperity. However, over time, it became clear that the development of economic activity has not only a positive impact, but also side effects, such as environmental degradation and a reduction in quality of life. The initial assumption that the pursuit of enterprises to maximize revenue leads undoubtedly to social welfare have begun to be questionable and the negative aspects of human activity have contributed to the environmental imbalance, and thus threat to human health. Therefore, in these days the enterprises, in particular multinational firms, experience increased pressure by numerous stakeholders to engage in social as well as environmental responsibility. The issue particularly refers to multinational corporations as the process of globalisation have caused the concerns that multinational companies might be pursuing profit at the expense of vulnerable workforces, environmental degradation and so on. Additionally, it has been already recognized that today stakeholders are not only concerned about profits. They become more interested in the enterprises' activities in terms of various economic, environmental, ethical, governance, and social aspects, since these factors significantly impact the fate of the firm in the long term. This growing pressure toward meeting social and economic performance demands from various groups of stakeholders results in the fact that companies all over the world pay more attention to the integration of the dimensions of responsibility in their operations. It is visible that today the enterprises, particularly multinational corporations implement several actions 
aimed at social development and supporting society as a whole or at preventing environment pollution and degradation (Porter and Kramer 2006; Petrović-Randelović et al. 2015). Through pursuing different activities corporations aim at compensating for the negative consequences of their operations. Taking the above said into consideration, it seems that today acting socially and ethically is rather a requirement or even coercion than a competitive advantage of companies.

The aim of the paper is to explore Starbucks' activities in the field of CSR. Nowadays, sustainable development and social activities are important and even necessary to run a growing business. Starbucks company is very interesting when it comes to this aspect because it is a global (multinational) corporation that is very successful and as a result is a market leader in its industry. What's more, the company manages to run a business in a challenging environment. The increasingly worsening climate has consequences such as the compulsion to reduce carbon dioxide production or the reduction of wastes, while Starbucks is developing from year to year, using new technologies while limiting its impact on the environment. Furthermore, the company conducts broadly understood activities aimed not only at limiting the negative impact of its activities but also contributes to helping other people and organizations. The authors therefore intend to study how Starbucks deals with corporate social responsibility in social, ethical and environmental matters. The research process is driven by the three following research questions: (1) What are the main Starbucks' company objectives in the field of CSR? (2) What are the main areas of Starbucks' involvement in CSR activities? (3) How does Starbucks implement CSR activities following TBL concept?

\section{The idea behind CSR concept}

CSR is treated as an interdisciplinary and multidimensional phenomenon, which implies several ways of understanding its essence. The meaning of corporate social responsibility concept has evolved together with the development of globalization and increased competition due to internationalization. Over time the researchers and practitioners have provided various definitions of CSR highlighting diverse aspects regarding firm's management. However, despite multiple CSR definitions proposed in the literature, yet there is not a commonly 
definition of the term (Matten and Moon 2008; Nasrullah and Rahim 2014). An interesting study regarding CSR meaning and evolution has been done by Sarkar and Searcy (2016), who examined 110 CSR definitions presented in the works published in peer reviewed journals, books, and non-academic publications in the period 1953-2014. The aforesaid authors categorized the identified CSR definitions into three periods showing the evolution of the term. The definitions assigned to the first period (1953-1982) emphasize mainly that, apart from having economic and legal obligations, business organizations have also some social responsibilities that they should meet voluntarily. The second period encompasses the works published from 1983 till 2002. Most of them highlight the ethics-related aspects of CSR, however several focus on environmental and stakeholder concerns. Finally, CSR definitions assigned to the third period (2003-2014), clearly emphasize environmental, stakeholders as well as ethical concerns in regard to CSR essence (Sarkar and Searcy, 2016).

The European Commission describes CSR as business organizations' responsibility for their impacts on society (European Commission, 2011). Similarly, the World Business Council for Sustainable Development provides a CSR definition, highlighting the commitment of business to contribute to sustainable economic development, working with employees, their families, the local community and society at large to improve their quality of life (World Business Council for Sustainable Development, 1999). Also the ISO 26000 standard refers to CSR indicating that CSR means organization's responsibility for the impact of its decisions and activities (products, service, processes) on society and the environment. The abovesaid document underlines that this can be achieved through transparent and ethical behaviour that contributes to the sustainable development, health and well-being of society, takes into account the expectations of stakeholders, follows the law in force and is consistent with international standards of behaviour (International Standard ISO 26000, 2010).

The common point of all above mentioned definitions is the idea that nowadays managing business should be based on the decisions and actions contributing not only to self-interest of the firm, but also to ensuring social wellbeing and protecting the environment, going beyond the issues required by the law regulations (Carroll, 1999; McWilliams and Siegel, 2000; McWilliams et al., 2006; Benn and Bolton, 2011; 
Rok 2013; Liczmańska-Kopcewicz et al., 2019, Sudolska and Łapińska, 2020).

As said above, the contemporary understanding of CSR is a holistic view of social, environmental, and economic responsibilities of business entities (Ashrafi et al., 2018). Such an approach directly refers to the triple bottom line theory referring to the balance between the economy, the environment and the society (Elkington, 1997; Parrish, 2007; Dahlsrud, 2008; Sarkar and Searcy, 2016). Contemporary companies that aspire to be recognized as implementing the CSR concept, aim at achieving economic objectives which are ecologically accepted and socially expected (Singh et al., 2019). The triple bottom line aims to achieve a balance between social, environmental and economic dimensions in a harmony. In accordance with the TBL concept, firms should concentrate on three different so-called bottom lines. The first bottom line is related to the financial dimension of a company, that is called 'Profit'. The second bottom refers to the degree of company's responsibility for social aspects and has been labelled 'People". This aspect includes fair and beneficial business practices towards employees, the community and the region in which the company operates. Organizations following TBL idea pay fair wages to their employees, they do not use children to work, they ensure the safety of the work environment, they observe the correct working time and they do not use the labour force. They also often try to support employees by providing health care and education etc. The third bottom line is called 'Planet' and is related to the degree of firm's environmental responsibility (Eklington, 1997; Robinson, 2004; Hahn et al., 2015; Lis et al., 2020). A company that operates in accordance with TBL strives to preserve the natural environment, reduces its environmental impact or harms it as little as possible. Reducing the impact on the environment is implemented by careful management of energy consumption and nonrenewable resources, reducing the amount of production waste and so forth. By applying TBL principles, companies avoid environmentally destructive practices, such as overfishing or threatening to run out of resources. What is of high importance, the TBL concept calls to measure firm's success according the above mentioned three perspectives: people, planet and profits (Elkington, 1997). Its performance in each category represents its perceived commitment to the stakeholders, the natural environment and its economic results, respectively. 


\section{Research method}

The research method applied in order to achieve the aim of the paper is the single case study analysis of Starbucks' company. The major advantage of the case study method is using empirical evidence from real organizations to contribute to the knowledge in the field (Myers, 2010). The single case study enables to investigate thoroughly and to understand the unit of analysis within its context. In order to achieve the aim of the paper, the following study questions had been formulated:

Q1: What are the main areas of Starbucks' involvement in CSR activities?

Q2: What are the main Starbucks' company objectives in the field of CSR?

Q3: How does Starbucks implement CSR activities following the TBL concept?

Starbucks Corporation is an American chain of cafes that in these days is operating globally. A first coffee shop was opened in 1971 in Pike Place Market in Seattle. Contemporarily, Starbucks is the world's largest cafe chain. As of the first quarter of 2018, Starbucks has 27,339 retail locations in 74 countries. The three main markets Starbucks operates in are: the Americas, China and Asia Pacific, and Europe, Middle East and Africa. Starbucks is both a public and individual space where one can meet other people and be alone with oneself. From the beginning, creating such an opportunity for people was Starbucks' goal. The 'Starbucks experience' is therefore an opportunity to be together at a reasonable price (Schultz and Gordon, 2012).

Starbucks' company mission refers to inspiring and nurturing the human spirit - one person, one cup and one neighbourhood at a time. The company lives in accordance with the values important to it that include: creating a culture of warmth and belonging in which everyone is welcome, bold actions, continuous development and finding new ways to develop the company and employees as well as striving and taking responsibility for the company's results. Since its beginning Starbucks sought to conduct business in a manner that is friendly to both people and the environment. Nowadays, the company conducts broadly understood activities aimed not only at limiting the negative impact of its activities but also contributes to helping other people and organizations. However, the reason to start operating in CSR was also 
a market necessity, because at the end of the 1990s customers began to be more and more aware. Most people started buying from companies that they respected and trusted. Therefore, Starbucks began to undertake various activities that were to show respect for both the environment and people working on their products. Between 2000 and 2005, the company allocated over \$ 47 million to develop communities around the world.

The study was conducted in 2019. The data for the study has been gathered from the publications and reports published on Starbuck's company website (www.starbucks.com).

\section{Study results}

\subsection{General findings}

The conducted study allows to state that Starbucks sets goals in three key areas: leading in sustainability, strengthening communities and creating opportunities. The company is focused on these areas because they know that they can help and has the greatest influence on them. What is more, Starbucks is committed to the United Nations Sustainable Development Goals and treats these aims as support for their own social impact programs and cooperation with their customers, partners, non-governmental organizations and investors. These plans are to achieve a better and more sustainable future for everyone. They engage in global challenges that need to be confronted, including poverty, inequality, climate change, environmental degradation, prosperity, peace and justice.

The company's vision is to create positive changes by activating employees, customers and suppliers. Starbucks wants to be a leader and innovator of a society that promotes environmental protection and social well-being so that the world in which we live can serve not only the present generation but also the future ones. Starbucks believes in ethical business conduct and strives to conduct business in a way that helps to protect the company culture. Starbucks has a brochure to maintain the standards of business ethics which presents the company's expectations and the ability to adapt to its values and standards. In addition, Starbucks is committed to good management and social responsibility, which results in employee satisfaction and growing customer interest. Starbucks' social responsibility is focused on three pillars: communities, the environment, and ethical sourcing. 


\subsection{Starbucks' activities focused on communities}

Starbucks carries out several activities related to CSR focused on different aspects. The first of visible company's actions refers to refugee and veterans hiring. Starbucks strives to help refugee communities in creating new paths and building their future in the face of new and difficult circumstances, because thanks to work refugees integrate faster with their communities and this bring measurable economic and social benefits. Starbucks has a long history of investing in people and creating employment opportunities for them. The company has employed 1,672 refugees in the US, Canada and Europe until 2018, while by 2022 its goal is to employ 10,000 refugees. What Starbucks is trying to achieve is employing refugees in the markets where there is a lot such people. Persons willing to work will need a work permit and will undergo verification procedures such as checking their past. What is more, the company tries to provide additional support, resources or tools as part of the recruitment process so that refugees have the same opportunities to get a job as others. Starbucks actively cooperates with other organizations, among others by joining the UNHCR \#Withrefugees campaign and the Refugee Tent Partnership, exerting a joint positive effect on the welfare and life of refugees. Members of the coalition provide practical support to refugees in the fields of education, employment and shelter. Thanks to the fact that the coalition includes members from various industries and countries, this strengthens the global message of tolerance and integration. The company also cooperates with the most important refugee resettlement agencies and non-governmental organizations. These include: the International Rescue Committee, Employment of Immigrants, UNHCR- the UN Agency for Refugees. What is more, Starbucks financially supports specialized programs that are designed to train refugees and followingly prepare them for work. To raise funds for organizations that help refugees, Starbucks uses the scale of its digital platforms through social media, among others, to encourage its customers to support the Red Cross organization that helps refugees. Moreover, donations are also made by Starbucks employees. The Starbucks Foundation itself donate $\$ 75,000$ for food, medical care or shelter to the non-profit organization that helps refugee children called Save the Children. Additionally, the company helped Caritas by a donation of $\$ 15,000$ and Aktion Deutschland Hilft an alliance which helps refugees in Germany by donating $\$ 20,000$ for them. 
The company believes that thanks to veterans and military spouses, Starbucks is stronger and better. The company has employed 22,000 veterans and their spouses since 2013. The next goal was to employ 25,000 people from that group by 2025. This goal was exceeded six years ahead of schedule and moreover, the company plans new employment in the number of 5000 people belonging to this group annually. Starbucks not only offers employment, but also education. What's more, 60 military stores have been opened in the US, which are places for military families where they can work, spend time and give each other tips on changing their career path. By 2022, Starbucks plans to open another 70 of such stores.

Starbucks aimed to be a corporate spokesperson who talks about the transformation of the veterans and their families and also promotes a culture that supports military families. The company created the Starbucks Armed Forces Network (AFN) on Facebook, which was created to support war veterans in changing employment to civilian and to enable this community to support each other, educate or develop both professionally and socially. In addition, this network enables employees the opportunity to engage in integration and diversity by solving problems related to race, gender or sexual orientation.

Starbucks cooperates also with No One Left Behind. It is a nationwide association of war allies in the US, which strives to ensure that all allies are honored for courageous service during the war, and that they and their family members find security and opportunities. Unfortunately, there are still a lot of war allies who are in danger and waiting 2 to 3 years to process their visa application. The help consists in supporting people applying for a Special Immigration Visa to the USA so that they can be resettled to America and start a new life there. Starbucks, working with the association, enables these people to work. In addition, Starbucks supports efforts to create communities and positive interactions in places where such people live.

The next significant action aimed at supporting the community is creating Starbucks Foundation. The Starbucks Foundation was created because the company wanted to commit to strengthening the community. It began in 1997 and co-financed the literacy program in the USA and Canada. Whereas today the Foundation supports communities around the world, among others by helping organizations that create jobs and provide educational opportunities. Starbucks, starting with the 'Opportunities for All' initiative, focuses primarily on supporting 
refugees, veterans and military spouses as well as young people who are not studying or working. Only in 2018, the Starbucks Foundation supported over 47 such organizations with subsidies of \$ 1.3 million. In addition, in 2015, the company donated \$ 6.9 million to nonprofit organizations, which included, among others, grants for social development and Starbucks Opportunity for Youth Grants.

The foundation also supports communities that provide products such as tea, coffee or cocoa, because the company wants to invest in programs that will strengthen their social and economic development. The projects aim to increase access to education and agricultural training, health and standard of living as well as microfinance and microcredit services. What's more, Starbucks' branch- Ethos Water supports water programs, in particular it contributes to ensuring that all countries have access to clean water and to this purpose the foundation has transferred since 2005 \$ 13.8 million.

Another company's initiative referring to the social aspects and the support for community is the focus on creating a culture of belonging, inclusion and diversity. Starbucks is very focused on creating a culture of belonging, diversity and integration. This results in the fact that company's employees are diverse in terms of different views, sexual orientation, gender and origin. The company believes that diversity not only gives different experiences or culture, but also promotes innovation and economic growth. Since integration and diversity are an important issue in the company, eight partner networks have been created that represent integrative environments at Starbucks. These include: Starbucks Black Partner Network, Starbucks Pride Alliance Network, Starbucks Women's Development Partner Network, etc. The results and awards testify that the company does not make empty promises. One of the evidences is that Starbucks was chosen Disability Employer of the Year 2014 by the US Business Leadership Network. In 2015, Starbucks got a 100 percent mark on the Corporate Equality Index and in 2015 and 2016 the company received the highest score on the Disabled Equality Index.

Starbucks creates a fair environment for its employees, among others, by paying partners based on their experience, skills and performance, not on what gender they are. What's more, the company publishes information of annual progress in wages, job offers standards in order to determine salary as well as analyses of compensation decisions. Although equal pay has been a federal law in the United 
States since 1963, women still earn 80 cents, while men get a dollar for the same job. Starbucks has long been working to compensate for these differences. Therefore, the company has set itself the goal of paying equitable payments to employees of all genders and races performing similar jobs in the United States. The goal has been achieved in 2018 and the result was $100 \%$ of global gender equality in the United States and in 2019 the same happened in Canada and China. Starbucks strives to create a culture of belonging in many ways. They provide training and the necessary tools for managers which allow them to work in a way that supports diversity and an inclusive culture based on contribution. The company also provides education in this area for employees. The company strives for equal pay across the whole world. In addition, Starbucks joined the Employers for Pay Equity consortium to agree on equal pay principles with other companies to eliminate the pay gap between men and women. By working together, companies can eliminate the pay gap at a faster pace.

\subsection{Starbucks' activities focused on environment}

Starbucks is also very active in the field of the environment support. The company comprehensively supports sustainable development by paying attention to all aspects of its business activities. The company is guided by its values, engaging its employees and clients. Starbucks is always looking for solutions to make good changes. The company focuses on four areas in terms of the environment, it is: greener stores, greener cups and packaging, greener power and climate change.

A great and recognizable action regarding company's focus on the environment protection is called as 'Greener stores'. In 2001, Starbucks joined the US Green Building Council, which led to cooperation in developing the LEED (Leadership in Energy and Environmental Design) program for retail. Whereas Starbucks committed itself to designing and building 10,000 'Greener stores' around the world by 2025 in an effort to adapt LEED to the new design strategies and commercial interiors of their stores. 'Greener stores' are buildings that are both efficient and ecological. The first LEED certified store was opened in Oregon in 2005, and at the moment the number of certified stores is 1,600 in 20 countries around the world. The company thereby has become a leader in the development and implementation of green buildings for commercial companies. Thanks to continuous evolution, the company not only designs and builds stores in accordance with 
LEED standards, but also renovates old premises. What's more, a new program is being developed to check stores in order to carry out further innovations aimed at efficiency and sustainable development. Thanks to cooperation with SCS Global Services, among others, the program provides opportunities to minimize environmental impact, contributing to a sustainable future. It is about achieving better energy and water efficiency, waste management or building from responsible materials. To achieve better performance at Greener stores, Starbucks focuses on several aspects. The first one is energy efficiency and water management, thanks to which water savings are 30\% and energy $25 \%$ compared to using these two resources with the old style of building stores. The second aspect is the use of renewable energy: solar and wind in $100 \%$ consumption. Another aspect that helps achieve better performance of new stores and improves the well-being of employees and customers is a healthy environment, which is built, among others, by the right temperature, lighting, noise and air quality. The next important element is the acquisition and use of materials and products for the store in a responsible, sustainable manner. In addition, waste diversion is very important, created in order to reduce the amount of waste and transfer unsold food to food banks. The last but not least aspect is the involvement of partners to act and engage in sustainable development practices.

Another interesting initiative in the area of environment protection and support has been labelled 'greener cups and packaging'. By 2022, Starbucks' goal is to double the content of recyclables in cups and to discover cups that will be $100 \%$ compostable and recyclable. It can be easily seen that the company works comprehensively for the benefit of the environment, reducing waste and discovering the latest technologies towards the possibility of reusing these cups and other packaging. Starbucks is constantly working to reduce the environmental impact of both cups and lids. Already in 1997, the company found a way to eliminate a double cup by introducing a sleeve with a hot cup. Whereas in 2006 Starbucks was the first to introduce the production of cups from recycled material, then it was $10 \%$ of material per cup. In addition, in 2016 cup lids were introduced, which are also recyclable. To reduce waste and opt out of plastic and paper cups, Starbucks has offered reusable cups since 2013. Moreover, those customers who bring their cups receive attractive discounts from the company. When it comes to plastic straws, the company has committed to withdraw them 
completely in all stores by 2020 . The new straws will be recyclable and mainly made of paper. As a result, it is possible to eliminate up to 1 billion plastic straws a year.

Since 2018, Starbucks together with employees have initiated cooperation with industry entrepreneurs to identify and introduce even better solutions in the field of recycling cups. At present, recycling is not a simple thing and customers have a problem where and when they can recycle their cup through constantly changing regulations and different policies of individual self-governments. Starbucks stands for best practices and model regulation and by working with the National League of Cities, provides clearer information on what materials can be composted and recycled. In addition, the company cooperates with various companies, not only from the industry but also from the entire supply chain, as a member of the Paper Recovery Alliance and Plastics Recovery Group.

The next area of Starbucks' focus on environment protection refers to supporting 'greener energy' production. Starbucks has invested \$ 140 million in renewable energy since 2005, supplying stores with green energy and thereby reducing environmental impact and facilitating access to this energy in the communities in which the company operates. Thanks to such investments, Starbucks is able to supply energy to 9,000 stores in the United States and $77 \%$ of global operations. Renewable energy not only reduces pollution by improving air quality, but also reduces global warming by softening the climate. When in 2004 the company conducted research of greenhouse gas from their stores, which showed that $70 \%$ comes from electricity, they decided to invest in renewable energy. Thanks to continuous investments and obtaining renewable energy certificates, the company got 100 percent of global stores' supply by renewable energy. What's more, in 2015 Starbucks became a member of RE100, thus committing itself to using $100 \%$ renewable energy. Whereas in 2019 , the company became one of the largest recipients of this energy by the Environmental Protection Agency in the USA. One of Starbucks' investments is a 140,000-acre solar farm in North Carolina, which supplies over 600 stores of the company. In addition, thanks to cooperation with Puget Sound Energy in Washington, more than 100 stores and a coffee roaster in Kent are powered by wind energy. Cooperation with international partners allows to identify and plan the best type of renewable energy in specific areas for the future. 
Carrying out its activities, the company pays also attention to the issue of climate change. Changing climate, less rainfall and increased erosion are reducing the area for coffee growing all over the world. Thus, the company invests in solutions and strategies that help counteract climate change because if the climate worsens, it will significantly affect the area of agriculture. Starbucks set its goals and strategies for climate change in 2004, which mainly concern saving energy and changing energy in stores for renewable. The company is also keen to encourage other companies and organizations to join the progressive climate change policy.

Every year, Starbucks conducts an inventory of its greenhouse gases by assessing emissions from global retail stores, manufacturing operations and purchased goods and services. Scope 1 is direct greenhouse gas emissions from stores, manufacturing plants or Starbucks vehicles. In scope 2 it can be found the electricity emissions consumed by the company, which is low due to the use of renewable energy. The largest emissions were recorded in scope 3, which includes purchased goods and services. This inventory shows that emissions from these three ranges amounted to 16581000 tonnes of carbon dioxide equivalent.

\subsection{Starbucks' activities focused on ethical sourcing}

To ensure the high quality of products and guarantee their continuous delivery, and thus firm's profitability, Starbucks helps farmers and suppliers to produce them in an ethical way. In cooperation with Conservation International, the company is obliged to buy coffee that is $100 \%$ derived from ethical sources. In the face of challenges facing farmers and to improve sustainability, the company uses many helpful practices. As mentioned before, thanks to the Global Farmer Fund program, Starbucks invests in helping farmers \$ 50 million. The company shares research with Farmers' Support Centers or donates disease-resistant trees. Starbucks also belongs to the Sustainable Coffee Challenge industry group that is working to make coffee the first sustainable agricultural product.

Another important program in which Starbucks has participated since 2004, cooperating with the non-profit organization Conservation International is The Coffee and Farmer Equity (C.A.F.E.) Practices. These are comprehensive quality, environmental, social and economic guidelines that verify whether coffee is obtained in an ethical manner 
and, if not, determine how it should be done. This helps to assess the company which supply chain produces the best coffee and which does it in the most socially responsible way. Starbucks has bought coffee for the last four years in a row, 99\% of which has been confirmed by C.A.F.E. practices. The company's current goal is to obtain $100 \%$ ethically grown coffee. Standards of practice are stringent, but worthwhile as they promote the quality of coffee and allow farmers to grow crops in a sustainable way. The program's checklist includes the product, people and the planet. In the first place, elements related to people are controlled, among others, earnings, medical care or living conditions. Moreover, child labour is completely unacceptable. When it comes to environmental issues, many elements are verified, such as soil care and deforestation, wildlife conservation, and water and energy consumption. Whereas the product is to be of high quality and farmers are to receive fair salary for its production.

Starbucks' next goal is to acquire $100 \%$ tea from ethical sources by 2020 . In 2018, tea obtained was determined to be $95 \%$ ethically produced. As in the case of coffee, thanks to ethical production of tea, the durability of the supply chain, the economic situation of employees and farmers in the environment are improved. The company buys tea from its growers from around the world who are specialized in its production and the product itself is of the highest quality. Starbucks has been cooperating with the Ethical Tea Partnership (ETP) for 10 years, thanks to which one can be sure that the teas that the company buys are produced in accordance with the principles of sustainable development, and what's more it happens in safe and humane working conditions.

Another Starbucks' goal associated with cocoa is its $100 \%$ ethical sourcing by 2020. As with coffee and tea, the company aims to ensure long-term cooperation with suppliers, maintain high quality of cocoa and furthermore a positive impact on society and the environment. In 2008, COCOA practices were introduced, which were inspired by the C.A.F.E. Practices. This program explores the cocoa supply chain and educates on the sustainable development of producers and buyers. Moreover, it has identified key areas that need improvement. In this case they are also independent organizations that carry out verifications. Starbucks has been supporting the World Cocoa Foundation since 2008, which works to ensure the sustainable development of cocoa, support for farmers so that cocoa is of the highest quality and the well-being of cocoa growers around the world. 


\section{Discussion and conclusions}

Concluding, the study examined the activities pursed by Starbucks company in the field of CSR with particular focus on the TBL idea. The conducted study allowed to answer the research questions that have been addressed. Thus, we assess that the aim of the paper has been achieved.

Posing the first research question we referred to company's activities in accordance with TBL concept. As the study results prove, Starbucks is very active in the area of environment support and protection in order to resist climate change and achieve a better future for the next generations. Furthermore, social aspects are the focus of the company. Starbucks conducts multiple actions aimed at supporting several local communities. All these activities lead to firms' financial performance and profitability that enables to invest in the environment protection, communities development or ethical sourcing.

Addressing the second question we wanted to find out the main objectives that the company set in regard to CSR concept. Study results indicate that one of Starbucks' objectives in regard to CSR is strengthening different communities. The community that is particularly focused on by the company are military veterans. The company objectives include veterans' employment as well as education. Additionally, the company promotes the culture supporting military veterans and their families. The next example of strengthening particular community refers to providing access and training for the communities of tea, coffee and cocoa suppliers. Starbucks also focuses a lot on the community made up of the company's employees. Another area of many activities pursued by Starbucks is the natural environment and its protection. The company aims at energy efficiency, water management, waste management etc. Another firm's objective in the field of CSR concept refers to ethical sourcing. Starbucks invests a lot to support farmers and enhance the sustainability along the whole company's supply chain.

Raising the last research question we consulted an issue of the ways that Starbucks implements CSR activities following the TBL concept. The results presented in the paper indicate that the company has a variety of activities at its disposal. Starbucks' focus on the bottom line labelled 'People' is highly visible in its everyday life. The company cares about the well-being of its employees as well as takes care of 
different communities outside company. Also firm's orientation on the bottom line called 'Planet' has been proved by the study results. As described above, Starbucks shows a significant level of responsibility towards the environment. Exploring company's activities one can easily notice the commitment to cope with the global challenges. Of course, also the bottom line labelled 'Profit' is a point of company's interest. The examples of Starbucks' activities focused on the environment protection or communities support are possible due to gaining profits necessary for any company to survive and develop. While interpreting company's activities in terms of the TBL concept, it is important to highlight that in accordance with the TBL idea, profits will help empower and sustain the community as a whole.

Summing up, the study offers an empirical evidence that it is possible to engage in all three areas that constitute the TBL concept. Despite investing a lot in different projects related to CSR implementation, the company stays profitable and is still growing worldwide. Since 2015, the company's earnings per share have been growing and the shareholders have been given large portions (https://www.marketbeat. com/stocks/NASDAQ/SBUX/earnings/).

Finally, we are aware of the limitations of the conducted study. The applied methodology of the single case study analysis allows to investigate particular issues in the given context, which is its primary advantage. However, we are aware that generalizing on the basis of a single case study is impossible, unless it is a critical case (StrumińskaKutra and Koładkiewicz, 2012). Due to this, the constraints regarding the possibilities to build up generalizations should be pointed out as a limitation of the conducted study. Therefore, the results of the study are concerned as the contribution to further in-depth investigations and study replications in the context of other organizations.

\section{References}

Ashrafi, M., Adams, M., Walker, T. R., \& Magnan, G. (2018). How corporate social responsibility can be integrated into corporate sustainability: A theoretical review of their relationships. International Journal of Sustainable Development \& World Ecology, 25(8), 671-681.

Benn, S., \& Bolton, D. (2011). Key Concepts in Corporate Social Responsibility. London: Sage Publications.

Carroll, A. B. (1999). Corporate social responsibility: Evolution of a definitional construct. Business \& Society, 38(3), 268-295. 
Dahlsrud, A. (2008). How corporate social responsibility is defined: An analysis of 37 definitions. Corporate Social Responsibility and Environmental Management, 15(1), 1-13.

Elkington, J. (1997). Cannibals with Forks: The Triple Bottom Line of Sustainable Development. Oxford: Chapstone Publishing.

European Commission (2011). Communication from the Commission to the European Parliament, the Council, The European Economic and Social Committee and the Committee of the Regions: A Renewed EU Strategy 2011-14 for Corporate Social Responsibility. Brussels: European Commission. Retrieved from: https://eur-lex.eur opa.eu/legal-content/EN/TXT/PDF/?uri=CELEX:52011DC0681\&from=EN

Hahn, T., Pinkse, J., Preuss, L., \& Figge, F. (2015). Tensions in corporate sustainability: Towards an integrative framework. Journal of Business Ethics, 127(2), 297-316.

International Standard ISO 26000 (2010). Guidance on Social Responsibility. Geneva: International Organization for Standardization.

Liczmańska-Kopcewicz, K., Mizera, K., \& Pypłacz, P. (2019). Corporate social responsibility and sustainable development for creating value for FMCG sector enterprises. Sustainability, 11(20), art. 5808.

Lis, A., Sudolska, A., \& Tomanek, M. (2020). Mapping research on sustainable supplychain management. Sustainability, 12(10), art. 3987.

Matten, D, \& Moon, J. (2008). 'Implicit' and 'explicit' CSR: A conceptual framework for a comparative understanding of corporate social responsibility. Academy of Management Review, 33(2), 404-424.

McWilliams, A., \& Siegel, D. (2000). Corporate social responsibility and firm financial performance: Correlation or misspecification?. Strategic Management Journal, 21, 603-609.

McWilliams, A., Siegel, D., \& Wright, P. M. (2006). Corporate social responsibility: strategic implications. Journal of Management Studies, 43(1), 1-18.

Myers, M. D. (2010). Case study research. In M. Frenz, K. Nielsen, \& G. Walters (Eds.) Research Methods in Management (pp. 227-248). London: SAGE.

Nasrullah, N.M., \& Rahim, M.M. (2014). CSR in Private Enterprises in Developing Countries: Evidences from the Ready-made Garments Industry in Bangladesh. Cham: Springer International Publishing.

Parrish, B. D. (2007). Designing the sustainable enterprises. Futures, 39(7), 846-860.

Petrović-Randelović, M., Stevanović, T., \& Ivanović-Dukić, M. (2015). Impact of corporate social responsibility on the competitiveness of multinational corporations. Procedia Economics and Finance, 19, 332-341.

Porter, M. E., \& Kramer, M. R. (2006). Strategy and society: The link between competitive advantage and corporate social responsibility. Harvard Business Review, 84(12), 78-92.

Robinson, J. (2004). Squaring the circle? Some thoughts on the idea of sustainable development. Ecological Economics, 48(4), 369-384.

Rok, B. (2013). Podstawy odpowiedzialności społecznej w zarzq̨dzaniu. Warszawa Wydawnictwo Poltext.

Sarkar. S, \& Searcy. C. (2016). Zeitgeist or chameleon? A quantitative analysis of CSR definitions. Journal of Cleaner Production, 135, 1423- 1435.

Schultz, H., \& Gordon, J. (2012). Starbucks: Sztuka wyciqgania wniosków z porażek, czyli rewolucyjny przepis Schultza na wielki sukces. Kraków Znak. 
Singh, A., Kar, S., \& Pamucar, D. (2019). Stakeholder role for developing a conceptual framing of sustainability in organization. Sustainability, 11(1), art. 208.

Strumińska-Kutra, M., \& Koładkiewicz, I. (2012). Studium przypadku. In: D. Jemielniak (Ed.), Badania jakościowe: Metody i narzędzia (pp. 1-40). Warszawa: PWN.

Sudolska, A., \& Łapińska, J. (2020). Implementation of the CSR concept through sport sponsorship: The case of the Polish Chemical Capital Group. Journal of Physical Education and Sport, 20(2), 1100-1105.

World Business Council for Sustainable Development (1999). Corporate Social Responsibility: Meeting Changing Expectations. New York: World Business Council for Sustainable Development. 
